ENCYCLOPEDDIE Encyclopédie berbère

BERBERE

$25 \mid 2003$

25 | Iseqqemâren - Juba

\title{
Les jeux chez les Ayt Mgild du Moyen-Atlas
}

(région d'Azrou-Aïn-Leuh)

\section{Claverie}

\section{OpenEdition}

\section{Journals}

Édition électronique

URL : http://journals.openedition.org/encyclopedieberbere/1509

DOI : 10.4000/encyclopedieberbere.1509

ISSN : 2262-7197

Éditeur

Peeters Publishers

Édition imprimée

Date de publication : 1 septembre 2003

Pagination : 3890-3891

ISBN : 2-7449-0424-4

ISSN : $1015-7344$

Référence électronique

M. Claverie, «Les jeux chez les Ayt Mgild du Moyen-Atlas », Encyclopédie berbère [En ligne], 25 | 2003,

document J10b, mis en ligne le 01 juin 2011, consulté le 25 septembre 2020. URL : http://

journals.openedition.org/encyclopedieberbere/1509; DOI : https://doi.org/10.4000/

encyclopedieberbere.1509

Ce document a été généré automatiquement le 25 septembre 2020

(c) Tous droits réservés 


\title{
Les jeux chez les Ayt Mgild du Moyen-Atlas
}

\author{
(région d'Azrou-Aïn-Leuh)
}

\section{Claverie}

1 Les enfants Ayt Mgild possèdent une gamme très complète de jeux et font preuve d'une grande adresse. Claverie ("Jeux berbères (région d'Azrou)», Hesperis, VIII, 1928, p. 401-403) en fit le recensement d'où nous extrayons les exemples suivants :

\section{Azab}

2 Les enfants se rassemblent et se mettent en rond. L'un d'eux, au milieu, surveille ses camarades qui essaient de le frapper en disant : «Azab! azab !...» Lui, se défend avec son pied droit, et fait face à ses adversaires en pivotant sur le pied gauche.

3 S'il touche quelqu'un, il sort. Il est remplacé par celui qui a été touché. S'il ne peut atteindre personne il doit subir dix coups et ses camarades crient: "hamar! hamar !...»

\section{Herša}

4 Les enfants forment un cercle. Un seul se met au milieu à quatre pattes. Les autres tournent et le frappent avec les mains. Lui se défend avec son pied droit, à la manière des chevaux. S'il réussit à toucher quelqu'un, celui-ci le remplace au milieu du cercle.

\section{Arba šbar}

5 Les enfants jouent par groupes de quatre. Deux sont assis sur le sol, face à face, leurs pieds se touchant. Ils placent sur leurs orteils, grande ouverte et en hauteur, une main, puis deux, trois et enfin quatre. Les deux autres partenaires sautent ces divers 
obstacles. Lorsqu'ils touchent leurs camarades, ils les remplacent et ceux-ci sautent à leur tour.

\section{Jaja amia qurqur}

6 Les enfants forment le cercle. Deux se placent au milieu et se bandent les yeux avec un turban. Le premier prend une boîte en fer-blanc et une pierre : il frappe sur la boîte par intervalles, puis se déplace doucement. Le deuxième, muni d'un turban, cherche à frapper son camarade.

\section{Tikua'(jeux d'osselets)}

7 Les jouets sont des osselets de moutons : ils ont une forme rectangulaire. Chaque enfant a le sien. Deux, trois ou quatre jouent ensemble. Ils jettent en même temps les osselets, qui se présentent debout ou à plat.

Premier cas : un osselet debout, les autres à plat; le propriétaire du premier frappe sur l'osselet placé le plus près du sien, puis continue. S'il le manque, celui dont l'osselet était visé frappe sur un des autres de la même manière.

9 Deuxième cas : deux osselets debout, deux à plat. Les propriétaires des deux premiers tirent chacun sur un osselet placé à plat.

10 Troisième cas : trois osselets debout, un à plat celui dont l'osselet est à plat tire sur les autres. A gagné celui qui a touché tous les osselets.

11 Les enfants colorent leurs osselets de rouge, de jaune, ou de vert, afin de les reconnaître.

\section{Tiyemmi i'aban}

12 Les enfants se partagent en deux camps. Une première moitié s'enfuit autour du douar ; l'autre moitié poursuit ceux du deuxième camp qui atteignent les premiers, montent sur eux et leur font faire trois fois le tour du douar.

\section{Qašbu}

13 Les joueurs se divisent en deux camps. Entre ceux-ci une grosse pierre est placée. C'est le but. Avec des projectiles quelconques, pierres, balles..., deux joueurs (un de chaque camp) essaient de toucher le but. Celui qui n'y arrive pas est éliminé, et est remplacé par un partenaire. L'adversaire plus adroit reste. Lorsque tous les joueurs d'un camp sont éliminés, ce camp a perdu la partie.

\section{Imnayn wayur}

Les joueurs forment deux camps. Le premier forme un cercle. Les enfants du deuxième montent sur les premiers. Un cavalier descend et pince la joue d'une monture 
quelconque. Si celle-ci devine qui l'a pincé, les rôles sont échangés. Dans le cas contraire, tout le monde garde sa place.

\section{Iseggur} chaque coup, il prend une pierre de sa réserve avec la main droite, la lance en l'air, saisit une ou plusieurs pierres à récupérer et, toujours de la même main, il reprend celle qu'il a lancée en l'air.

18 S'il manque son coup une seule fois, son camarade de droite continue à jouer ; il a perdu la partie.

19 S'il ne prend qu'une partie des pierres à récupérer, il a gagné partiellement et son camarade de droite continue.

20 S'il a récupéré toutes les pierres, il a gagné la partie.

\section{Hî}

21 Les enfants jouent à " hî » au printemps. Ils choisissent dans le douar un emplacement net d'herbes et de pierres. Ils forment un cercle. L'un d'eux se place au milieu.

22 Ses camarades le frappent avec les mains en disant : « Hî, hî !... » Lui se défend avec son pied droit et tourne sur son pied gauche. S'il touche quelqu'un, celui-ci le remplace. Ils jouent ainsi jusqu'à la fatigue.

\section{INDEX}

Mots-clés : Ayt Mgild, Enfant, Ethnographie, Kabylie, Moyen-Atlas, Sahara, Touareg 